\title{
Prevalência de anticorpos anti-Toxoplasma gondii e anti-Neospora caninum em rebanhos caprinos do município de Mossoró, Rio Grande do Norte
}

Júlia Teresa Ribeiro de LIMA $^{1}$ Sílvia Maria Mendes AHID ${ }^{1}$ Raimundo Alves BARRÊTO JÚNIOR ${ }^{1}$ Hilda Fátima de Jesus PENA² Ricardo Augusto DIAS² Solange Maria GENNARI²

\section{Correspondência para:}

sgennari@usp.br

Recebido para publicação: 20/04/2007 Aprovado para publicação: 22/11/2007

\author{
1 - Departamento de Ciências Animais da Universidade Federal Rural do Semi-Árido, \\ Mossoró - RN \\ 2 - Departamento de Medicina Veterinária Preventiva e Saúde Animal da Faculdade \\ de Medicina Veterinária e Zootecnia da Universidade de São Paulo, São Paulo - SP
}

\section{RESUMO}

A toxoplasmose é uma doença que acomete todos os animais endotérmicos, inclusive o homem. Nos caprinos pode causar transtornos reprodutivos, gerando grandes perdas econômicas. O Neospora caninum foi recentemente reconhecido e, apesar de causar problemas reprodutivos em caprinos, ainda são poucos os trabalhos realizados nesta espécie. Com o objetivo de verificar a soroprevalência destes agentes em caprinos do município de Mossoró, Rio Grande do Norte, amostras de soro de 381 animais (324 fêmeas e 57 machos) de 14 propriedades foram testadas pela Reação de Imunofluorescência Indireta a partir das diluições 1:64 e 1:50 para Toxoplasma gondii e $N$. caninum, respectivamente. Das 14 propriedades, $13(92,8 \%)$ apresentaram animais soropositivos para $T$. gondii e quatro $(28,6 \%)$, para $N$. caninum. Dos 381 animais amostrados, 65 estavam positivos para $T$. gondii $(17,1 \%)$ e quatro $(1,05 \%)$ para $N$. caninum. Não houve associação estatística entre a soropositividade aos agentes e o sexo, a presença de problemas reprodutivos e a presença de cães e/ou gatos nas propriedades. Os resultados indicaram uma baixa soroprevalência ao $N$. caninum no município, enquanto $T$. gondii encontra-se disseminado nos rebanhos caprinos da região.

\section{Introdução}

A toxoplasmose é uma zoonose de distribuição cosmopolita que acomete o homem e outros animais endotérmicos (mamíferos e aves) e tem como agente causador o protozoário Toxoplasma gondi. ${ }^{1}$

Os caprinos podem ser seriamente acometidos pelo T. gondii, e a infecção durante a prenhez pode ocasionar vários transtornos reprodutivos, acarretando grandes perdas econômicas. ${ }^{2}$ Em 1979, a toxoplasmose foi descrita pela primeira vez como importante causa de prejuízos reprodutivos em caprinos ${ }^{3} \mathrm{e}$, apesar de menos documentada nesta espécie, há evidências de que os danos são maiores, acometendo clinicamente também animais adultos ${ }^{4}$.

\author{
Palavras-chave: \\ Caprinos. \\ Toxoplasma gondii. \\ Neospora caninum. \\ Estudos soroepidemiológicos.
}

Neospora caninum, devido à grande similaridade morfológica, durante muito tempo foi confundido com $T$. gondii, sendo reconhecido como um novo gênero e espécie após o isolamento em cultura de cérebro de cão infectado congenitamente. ${ }^{5}$ Apesar de fazerem parte do mesmo filo (Apicomplexa, família Sarcocystidae), estudos utilizando microscopia eletrônica revelaram pequenas diferenças morfológicas ${ }^{6} \mathrm{e}$ sorológicas entre estes parasitas.

O Rio Grande do Norte possui o sexto maior rebanho caprino do país e no município de Mossoró, a caprinocultura se destaca como a mais importante atividade pecuária. ${ }^{7}$ Estudo realizado pelo Sebrae-RN apontou a elevada taxa de mortalidade dos animais, como um dos principais obstáculos ao melhor desempenho desta atividade ${ }^{8}$, 
entretanto o papel do T. gondii ou do $N$. caninum como possíveis agentes responsáveis por problemas na caprinocultura do estado ainda não foi determinado. Assim, o objetivo deste estudo foi avaliar a soroprevalência do T. gondii e do N. caninum nos rebanhos caprinos da região, bem como avaliar a associação com possíveis fatores de risco para a infecção pelos agentes.

\section{Material e Método}

O estudo foi realizado em 14 propriedades rurais do município de Mossoró, no Estado do Rio Grande do Norte. O tamanho da amostra foi determinado a partir do número estimado de 17.477 caprinos no município ${ }^{8}$, utilizando o programa estatístico Win Episcope 2.0, com freqüência esperada de $50 \%$ e com grau de confiança igual a $95 \%$. Estes parâmetros forneceram um número de 376 animais a serem examinados. A escolha das 14 propriedades foi arbitrária, de modo a abranger, geograficamente, todo o território do município. Como critério de inclusão dos animais na amostra, selecionaram-se todos os caprinos com idade superior a um ano, completando-se um tamanho de amostra de 381 caprinos, sendo 324 fêmeas e 57 machos.

As amostras de soro sangüíneo foram submetidas à Reação de Imunofluorescência Indireta (RIFI) para detecção de IgG antiT. gondii ${ }^{9}$, considerando-se a diluição de 1:64 como ponto de corte ${ }^{10,11,12}$. Como antígeno, foram utilizados taquizoítos da amostra $\mathrm{RH}$ de T. gondii, mantidos em camundongos.

Para a detecção da presença de anticorpos anti-N. caninum, as amostras foram submetidas à RIFI ${ }^{5}$, utilizando o ponto de corte na diluição de 1:50 ${ }^{10,13,14}$. Como antígeno, taquizoítos de N. caninum (amostra NC-1) foram mantidos por passagens contínuas em cultura de células VERO.

Foram incluídos soros controle positivo e negativo de origem caprina em ambos os testes. O conjugado utilizado nas reações foi anti-IgG caprina, produzida em coelhos e marcada com isotiocianato de fluoresceína (Sigma ${ }^{\mathrm{O}}$ F7367), na diluição de 1:2000 em solução de PBS 7,2 contendo Azul de Evans 0,01\%. As reações foram consideradas positivas quando os taquizoítos apresentavam fluorescência periférica total e as amostras de soro reagentes foram tituladas até a obtenção da maior diluição positiva na RIFI.

Possíveis associações entre sexo, relato de problemas reprodutivos e presença de gatos e/ou cães nas propriedades, ingestão de placenta pelos cães e a positividade ao $T$. gondiii ou ao $N$. caninum foram verificadas através do Teste Qui-quadrado $\left(\div^{2}\right)$ quando possível e, quando não, utilizou-se o Teste Exato de Fischer.

\section{Resultados}

Das 14 propriedades examinadas, 13 (92,9\%) tiveram pelo menos um animal soropositivo para T. gondii. A prevalência nestas propriedades esteve entre 5 a 58,8\% (Tabela 1), com 65 animais soropositivos $(17,1 \%)$ com títulos de 64 (4 caprinos), 128 (8 caprinos), 256 (18 caprinos), 512 (15 caprinos), 1024 (dois caprinos), 2048 (oito caprinos), 4096 (quatro caprinos), 8192 (seis caprinos). Prevalências semelhantes ( $\mathrm{p}>0,05)$, de $17 \%$ e $17,5 \%$, foram encontradas para fêmeas e machos, respectivamente.

Em 10 propriedades $(71,4 \%)$ foi relatada a presença de problemas reprodutivos nas fêmeas, porém somente em sete delas, nas quais foram amostradas 188 fêmeas, estes problemas eram informados individualmente. Das 39 fêmeas relacionadas com problemas reprodutivos $(20,7 \%)$, apenas três $(7,7 \%)$ apresentaram anticorpos anti-T. gondii.

Foi observada a presença de gatos em $11(78,6 \%)$ das 14 propriedades visitadas (Tabela 2) e em 64,3\% destas foi relatado o contato dos gatos com as pastagens e com os caprinos.

Em quatro propriedades amostradas $(28,6 \%)$ foram diagnosticados caprinos soropositivos para N. caninum, sendo um por propriedade, com valores de prevalência que variaram de $2,5 \%$ a $5 \%$ (Tabela 1 ). Dentre o 
Tabela 1 - Prevalência de anticorpos anti-Toxoplasma gondii e anti-Neospora caninum em caprinos por propriedade analisada do município de Mossoró, RN, pela RIFI $(\geq 1: 64)$

\begin{tabular}{ccccccc}
\hline \multirow{2}{*}{$\begin{array}{c}\mathbf{N}^{\circ} \mathbf{d a} \\
\text { Propriedade }\end{array}$} & $\begin{array}{c}\text { Total de } \\
\text { capprinos na } \\
\text { propriedade }\end{array}$ & $\begin{array}{c}\text { Caprinos } \\
\text { examinados }\end{array}$ & $\begin{array}{c}\text { Caprinos } \\
\text { Positivos }\end{array}$ & $\begin{array}{c}\text { Prevalência } \\
(\%)\end{array}$ & $\begin{array}{c}\text { Caprinos } \\
\text { positivos }\end{array}$ & $\begin{array}{c}\text { Prevalência } \\
(\%)\end{array}$ \\
\hline $\mathbf{1}$ & 500 & 31 & 12 & 38,7 & 1 & 3,2 \\
$\mathbf{2}$ & 130 & 25 & 10 & 40,0 & 0 & 0 \\
$\mathbf{3}$ & 600 & 32 & 3 & 9,4 & 0 & 0 \\
$\mathbf{4}$ & 70 & 20 & 3 & 15,0 & 1 & 5,0 \\
$\mathbf{5}$ & 560 & 48 & 3 & 6,2 & 0 & 0 \\
$\mathbf{6}$ & 200 & 24 & 2 & 8,3 & 1 & 4,2 \\
$\mathbf{7}$ & 90 & 16 & 9 & 56,2 & 0 & 0 \\
$\mathbf{8}$ & 170 & 17 & 10 & 58,8 & 0 & 0 \\
$\mathbf{9}$ & 135 & 20 & 1 & 5,0 & 0 & 0 \\
$\mathbf{1 0}$ & 90 & 12 & 1 & 8,3 & 0 & 0 \\
$\mathbf{1 1}$ & 500 & 40 & 3 & 7,5 & 0 & 0 \\
$\mathbf{1 2}$ & 160 & 20 & 2 & 10,0 & 0 & 0 \\
$\mathbf{1 3}$ & 300 & 36 & 0 & 0 & 0 & 0 \\
$\mathbf{1 4}$ & 800 & 40 & 6 & 15,0 & 1 & 2,5 \\
\hline Total & 4305 & 381 & 65 & 17,1 & 4 & 1,05 \\
\hline
\end{tabular}

total de caprinos, a soroprevalência observada para N. caninum foi de 1,05\% (4/ 381), com títulos de 200, 800, 1600 e 3200, sendo todas fêmeas $(1,2 \%)$ e, em nenhuma destas foi relatado problema reprodutivo. A presença de cães (Tabela 2) e o contato destes com os caprinos foram relatadas em 13 propriedades $(92,9 \%)$, o acesso dos cães às pastagens foi informado em 11 destas (78,6\%) e em 50\% das propriedades já foi observado cães ingerirem placenta das cabras.

Somente dois $(0,5 \%)$ animais foram diagnosticados como soropositivos para ambos os agentes, porém não apresentavam histórico de problemas reprodutivos.

Associação entre sexo, histórico de problemas reprodutivos e presença de cães ou gatos não apresentaram associação estatisticamente significante $(p>0,05)$ com a presença de anticorpos anti- $N$. caninum e anti-T. gondii.

\section{Discussão}

Das 14 propriedades examinadas, 13 $(92,9 \%)$ tiveram pelo menos um caprino soropositivo para T. gondii, indicando a alta disseminação deste agente em Mossoró-RN. Trabalhos realizados nos Estados de Minas Gerais ${ }^{15}$, São Paulo 10,16 e Paraná ${ }^{17}$, utilizando a RIFI com ponto de corte na diluição de 1:64 e na Bahia ${ }^{18}$ e Pernambuco ${ }^{19}$, usando a RIFI $\geq 1: 16$, encontraram caprinos soropositivos em todas as propriedades examinadas, confirmando a ampla presença deste agente nos capris de diferentes regiões do país.

Neste estudo, a prevalência por propriedade variou de 5\% a 58,8\%. Outros autores também observaram esta grande variação por propriedades 10, 15, 18, 19 , entretanto, devido às diferenças no ponto de corte utilizado nos diferentes estudos, a comparação dos valores obtidos deve ser evitada.

A prevalência de 17,1\% encontrada nas amostras examinadas neste trabalho foi inferior à observada nos de outros autores que obtiveram os valores $28,7 \%$ e $30,71 \%$, respectivamente, nos Estados de São Paulo ${ }^{10}$ e Paraná ${ }^{17}$, com o mesmo teste diagnóstico e ponto de corte. Em relação aos resultados obtidos em estudos realizados na região 
Tabela 2 - Relação entre a presença de gatos e cães nas propriedades e a prevalência de anticorpos anti-Toxoplasma gondii e anti-Neospora caninum em caprinos do município de Mossoró, RN

\begin{tabular}{ccccc}
\hline \multirow{2}{*}{$\begin{array}{c}\mathbf{N}^{0} \text { da } \\
\text { Propriedade }\end{array}$} & \multicolumn{2}{c}{$T$. gondii } & $\mathbf{N}^{\mathbf{0}}$ de cães & Prevalência (\%) \\
\cline { 2 - 5 } & $\mathbf{N}^{\mathbf{0}}$ de gatos & Prevalência (\%) & 15 & 3,2 \\
$\mathbf{1}$ & $*$ & 38,7 & 5 & 0 \\
$\mathbf{3}$ & 3 & 40,0 & 2 & 0 \\
$\mathbf{4}$ & 2 & 9,4 & 0 & 5,0 \\
$\mathbf{5}$ & 1 & 15,0 & 1 & 0 \\
$\mathbf{6}$ & 0 & 6,2 & 2 & 4,2 \\
$\mathbf{7}$ & 3 & 8,3 & 3 & 0 \\
$\mathbf{8}$ & 2 & 56,2 & $*$ & 0 \\
$\mathbf{9}$ & $*$ & 58,8 & 1 & 0 \\
$\mathbf{1 0}$ & 1 & 5,0 & 3 & 0 \\
$\mathbf{1 1}$ & 2 & 8,3 & 5 & 0 \\
$\mathbf{1 2}$ & 0 & 7,5 & 4 & 0 \\
$\mathbf{1 3}$ & 2 & 10,0 & 1 & 0 \\
$\mathbf{1 4}$ & 6 & 0 & 7 & 2,5 \\
\hline Total & 22 & 15,0 & 49 & 1,05 \\
\hline
\end{tabular}

* gatos avistados, mas em quantidade imprecisa devido à localização dos apriscos na parte urbana de um as sentamento rural.

nordeste, a prevalência no Rio Grande do Norte foi superior à obtida em Pernambuco $(10,33 \%)^{19}$ e na Bahia $(11,53 \%)^{18}$, mesmo tendo sido utilizado, no presente estudo, ponto de corte superior. As diferenças climáticas, presença de felinos, tipo de criação e manejo empregado podem justificar estas diferenças de resultados ${ }^{4}$.

Não houve diferença estatisticamente significante entre as soroprevalências observadas nas fêmeas $(17,0 \%)$ e machos $(17,5 \%)$. Mesmo achado foi relatado por outros autores ${ }^{19}$, entretanto, estudos realizados por Uzeda et al. ${ }^{18}$ encontraram diferença significativa com valores mais elevados nas fêmeas $(20,8 \%)$ do que nos machos $(2,2 \%)$.

Das 39 fêmeas nas quais problemas reprodutivos foram relatados, em apenas três, anticorpos anti- $T$. gondii foram encontrados. Apesar de alguns autores colocarem a toxoplasmose como a principal causa de aborto em pequenos ruminantes ${ }^{20}$, a relação entre soropositividade e a presença desse tipo de problema não foi observada neste trabalho e coincide com as observações de outro estudo ${ }^{19}$.

Não foi observada associação estatisticamente significante entre a presença de gatos e a soroprevalência para T. gondii nos rebanhos estudados, inclusive com o encontro de caprinos soropositivos em propriedades em que não havia a presença destes felinos. Fato não esperado foi o observado em uma daspropriedades, onde havia seis gatos e nenhum caprino amostrado foi soropositivo.

A baixa prevalência encontrada para $N$. caninum neste estudo $(1,05 \%)$ com valores variando de 2,5 a $5 \%$ nos rebanhos, mostra que a infecção por este parasita não é comum no município. Também foi considerada baixa a soroprevalência encontrada no Estado de São Paulo (6,34\%), apesar desta ter sido, aproximadamente, cinco vezes mais elevada ${ }^{10}$.Maiores valores foram observados no Estado da Bahia (15,0\%), onde encontraram 
associação com problemas reprodutivos e presença de cães ${ }^{21}$. No presente estudo, nenhuma dessas variáveis apresentou associação significante com positividade ao $N$. caninum, apesar dos cães terem contato com os caprinos (92,9\%), acesso às pastagens $(78,6 \%)$ e ser observada a ingestão da placenta das cabras pelos cães em metade das propriedades, indicando que, provavelmente, o agente esteja pouco disseminado também entre os cães da região.

\section{Conclusões}

A prevalência de infecção por $N$. caninum é baixa e a prevalência do $T$. gondii é alta nos rebanhos de caprinos do município de Mossoró, RN. O sexo dos caprinos, a existência de problemas reprodutivos nas fêmeas e a presença dos hospedeiros definitivos, cães e gatos, respectivamente, não apresentaram associação estatisticamente significante com a soropositividade aos agentes estudados.

\title{
Prevalence to Toxoplasma gondii and Neospora caninum antibodies in goats from Mossoró, Rio Grande do Norte
}

\begin{abstract}
Toxoplasmosis is a disease affecting all endothermic animals, including humans. Infection can cause reproductive failures that generate severe economic losses in goats. Neospora caninum is a protozoan recently recognized, also causing reproductive abnormalities in goats, but there are few studies. Serum samples from 381 goats (324 females and 57 males) bred in 14 farms from Mossoró County, Rio Grande do Norte State, northeastern region of Brazil, were tested to determine the prevalence of $T$. gondii and $N$. caninum using the indirect fluorescent antibody test. Sera that reacted to dilutions $\geq 1: 64$ and $\geq 1: 50$, respectively, were considered positive. In 13 farms (92.8\%), there were seropositive goats to T. gondii and in four farms $(28.6 \%)$, there were seropositive animals to $N$. caninum. T. gondii prevalence was $17.1 \%$ $(65 / 381)$ and $N$. caninum prevalence was $1.05 \%$ (4/381). There was no association between seropositivity to $T$. gondii or N. caninum and gender, presence of reproductive failures or presence of cats or dogs in the farms. Results indicate low N. caninum prevalence among goats from Mossoró County and T. gondii is widely distributed among goat herds in the same region.
\end{abstract}

\section{Referências}

1 DUBEY, J. P. Duration of immunity to shedding of Toxoplasma gondii oocysts by cats. Journal of Parasitology, v. 81, n. 3, p. 410-415, 1995.

2 DUBEY, J. P. Status of toxoplasmosis in sheep and goats in the United States. Journal of American Veterinary Medical Association, v. 196, n. 2, p. 259262, 1990.

3 MUNDAY, B. L.; MASON, R. W. Toxoplasmosis as a cause of perinatal death in goats. Australian Veterinary Journal, v. 55, n. 10, p. 485-487, 1979.

4 DUBEY, J. P. Toxoplasmosis in goats. Agri-practice, v. 8, n. 3, p. 43-52, 1987.
Key words:

Goats.

Toxoplasma gondii. Neospora caninum. Soroepidemiologic studies.
5 DUBEY, J. P. et al. Neonatal Neospora caninum infection in dogs: isolation of the causative agent and experimental transmission. Journal of American Veterinary Medical Association, v. 193, p. 1259-1263, 1988.

6 DUBEY, J. P.; LINDSAY, D. S. A review of Neospora caninum and neosporosis. Veterinary Parasitology, $\mathrm{v}$. 67, p. 1-59, 1996.

7 ANUALPEC. Anuário da pecuária brasileira. São Paulo: Instituto FNP, 2005. 340 p.

8 SEBRAE-RN. Diagnóstico da cadeia produtiva agroindustrial da caprinovinocultura do Rio Grande do Norte, SEBRAE, FAPERN, 2001. 224 p.

9 CAMARGO, M. E. Introdução às técnicas de Imunofluorescência. Revista Brasileira de Patologia 
Clínica, v. 10, n. 4, p. 143-171, 1974.

10 FIGLIUOLO, L. P. C. et al. Prevalence of antiToxoplasma gondii and anti-Neospora caninum antibodies in goats from São Paulo State, Brazil. Small Ruminant Research, v. 55, p. 29-32, 2004.

11 GARCIA, J. L. et al. Soroprevalência do Toxoplasma gondii em suínos, bovinos, ovinos e eqüinos e sua correlação com humanos, felinos e caninos, oriundos de propriedades rurais do norte do Paraná-Brasil. Ciência Rural, v. 29, n. 1, p. 91-97, 1999.

12 OPEL, U. et al. A survey of the prevalence of Toxoplasma infection in goats in New Zealand and a comparison of the latex agglutination and indirect fluorescence tests. Veterinary Parasitology, v. 40, n. 34, p. 181-186, 1991.

13 JOLLEY, W. R. et al. Repetitive abortion in Neosporainfected ewes. Veterinary Parasitology, v. 82, n. 3, p. 251-257, 1999.

14 LINDSAY, D. S. et al. Abortions, fetal death and stillbirths in pregnant pygmy goats inoculated with tachizoites of Neospora caninum. American Journal of Veterinary Research, v. 56, p. 1176-1180, 1995.

15 FIGUEIREDO, J. F. et al. Seroprevalence of Toxoplasma gondii infection in goats by the indirect haemaglutination, immunofluorescence and immunoenzymatic tests in the region of Uberlândia,
Brazil. Memórias do Instituto Oswald Cruz, v. 96, n. 5, p. 687-692, 2001.

16 MAINARD, R. S. et al. Seroprevalence of Toxoplasma gondii in dairy goats in the São Paulo State, Brazil. Revista da Sociedade Brasileira de Medicina Tropical, v. 36, n. 6, p. 759-761, 2003.

17 SELLA, M. Z. et al. Epidemiologia da toxoplasmose caprina: levantamento sorológico de Toxoplasma gondii em caprinos leiteiros na microrregião de Londrina, Paraná, Brasil. Revista Brasileira de Parasitologia Veterinária, v. 3, n. 1, p. 13-16, 1994.

18 UZÊDA, R. S. et al. Fatores relacionados à presença de anticorpos IgG anti-Toxoplasma gondii em caprinos leiteiros do Estado da Bahia. Revista Brasileira de Saúde e Produção Animal, v. 5, n. 1, p. 1-8, 2004.

19 SILVA, A. V. et al. Toxoplasmose em ovinos e caprinos: estudo soroepidemiológico em duas regiões do Estado de Pernambuco, Brasil. Ciência Rural, v. 33, n. 1, p. 115-119, 2003.

20 UNDERWOOD, W. J.; ROOK, J. S. Toxoplasmosis infection in sheep. The Compendium on Continued Education in Veterinary Practice, v. 14, n. 8, p. 15431549, 1992.

21 UZÊDA, R. S. et al. Seroprevalence of Neospora caninum in dairy goats from Bahia, Brazil. Small Ruminant Research, v. 70, n. 2-3, p. 257-259, 2007. 